\title{
Espelho da alma. Teoria social e subjetivação em um conto de Machado de Assis
}

\author{
| ${ }^{1}$ César Sabino, ${ }^{2}$ Madel Therezinha Luz |
}

Resumo: O objetivo deste trabalho é delinear de forma breve as interseçôes teóricas existentes no conto "O espelho. Um esboço de uma nova teoria da alma humana”, de Machado de Assis, e parte da tradição da teoria social que sugere uma síntese sociológica entre ação e estrutura relacionada ao aspecto da construção da identidade e subjetivação, reprodução e mudança social.

> Palavras-chave: teoria social; subjetivação; síntese sociológica; identidade.

\author{
1 Doutor em Antropologia \\ Cultural IFCS/UFRJ. Mestre \\ em Sociologia IFCS/UFRJ. \\ Pós-doutor em Saúde Coletiva. \\ IMS/UERJ. Professor Adjunto de \\ Sociologia do Departamento de \\ Estudos Políticos do Centro de \\ Ciências Jurídicas e Políticas da \\ Universidade Federal do Estado \\ do Rio de Janeiro. DESP/CCJP/ \\ UNIRIO. Endereço eletrônico: \\ cesarsabino@hotmail.com \\ ${ }^{2}$ Professora titular aposentada \\ do IMS-UERJ. Socióloga. \\ Doutora em Ciência Política \\ pela USP. Endereço eletrônico: \\ madelluz@superig.com.br
}




\section{O problema da ação e da estrutura}

Um dos aspectos da obra machadiana são os conflitos existenciais e a descrição da vida cotidiana brasileira no século XIX. O conhecimento científico, não raro, encontra interseções nas artes e na filosofia, ecos que ressaltam a singularidade do pensamento em todas as suas manifestaçôes. ${ }^{1}$ A obra literária de Machado de Assis é um exemplo de perspicácia psicológica, tensão filosófica e crítica sociológica, apresentando-se como corpo repleto de pontos de fuga cognitivos, verdadeiros desafios ao mesmo pensamento.

Nosso objetivo, neste texto, é buscar destacar os ecos - e por que não, as sugestôes - de parte do que supomos ser um esboço de teoria social implícita em um conto machadiano: "O espelho. Esboço de uma nova teoria da alma humana" (MACHADO DE ASSIS, 1998). Se ficção e sociologia são intercambiáveis, isto se deve ao fato de possuírem o mundo social como referência (BOURDIEU, 2002). Não queremos afirmar ou mesmo supor que a arte faz o trabalho da ciência ou vice-versa, ou que Machado de Assis era um produtor de teoria social antes de esta ter se consolidado como tal no Brasil, mas apenas apontar as possíveis instâncias de cruzamento e reverberações entre dois tipos de atividade intelectual.

O problema crônico da teoria social, a saber, a construção do objeto sociológico a partir da ação individual (subjetivismo), ou das estruturas (objetivismo), e a tentativa de resolução deste paradoxo, ou seja, sua síntese (BOURDIEU, 1989; GIDDENS, 1991; PARSONS, 1999; DOMINGUES, 2001; 2004; LIEDKE, 2007), parece surgir no destaque que a prosa machadiana confere à potência da ficção como pensamento (SHNAIDERMAN, 1994; PELOGGIO, 2005). O conto principia com cinco amigos debatendo a natureza da alma, sendo que um deles, justamente a personagem principal -, um homem abastado, "inteligente, não sem instrução... astuto e cáustico” (p. 28) -, denominado Jacobina, recusa-se a discutir a respeito de qualquer assunto, dizendo que: "a discussão é a forma polida do instinto batalhador, que jaz no homem como uma herança bestial...” (p. 29).

No início o autor aborda o que para ele significa o aspecto dúbio, dicotômico e mesmo trágico da mente ("da alma humana") incapaz de produzir uma conciliação lógica absoluta, inviabilizando a concepção da dialética hegeliana (LÉVI-STRAUS, 1974; DERRIDA, 1976; VERNANT, 1976; HEGEL, 1978; DELEUZE, 2000). De nossa perspectiva, em Machado de Assis, esta dualidade presente na polêmica é imanente - partindo das interações sociais para 
as representações, constituindo-se como a própria condição humana, pois sua

solução estaria restrita apenas a um suposto mundo sobrenatural e, portanto, não-humano, pois apenas "os serafins e querubins não controvertiam nada, e aliás, eram a perfeição espiritual e eterna” (idem), de acordo com a personagem.

Esta mesma dualidade lógica e prática considerada inerente ao pensamento poderia ser encontrada na análise que Émile Durkheim e Marcel Mauss realizaram sobre o totemismo, a qual destaca que a dinâmica do raciocínio só é possível porque através das classificações produzidas coletivamente, e a princípio, binariamente, por intermédio da concepção de sagrado (inclusão) e profano (exclusão), o ser humano estabeleceria hierarquias, organizando o pensamento e a realidade. ${ }^{2}$ Para o pai da escola sociológica francesa, o homem também seria composto por duas dimensões inseparáveis: a interior (mental) e a exterior (social), sendo que a primeira teria inscrita em sua realidade a plenitude da segunda, mais especificamente; e a segunda produziria os processos lógicos e representacionais da primeira (DURKHEIM; MAUSS, 2001).

No conto, podemos perceber a similaridade de concepções quando MachadoJacobina diz: "a perda da alma exterior implica a [a perda] da existência inteira" (p. 30). Tal afirmativa está diretamente relacionada à visão da dualidade da alma humana na qual o indivíduo e a pessoa apresentariam dois lados, interior e exterior, sendo que o último conferiria a consistência do primeiro, permitindo a este a articulação de uma pluralidade de papéis. Esse processo apenas seria possível porque a estrutura social, empírica e simbólica, estaria perpassada por relações de poder diretamente relacionadas às articulações epistêmicas ou estruturantes da realidade social (FOUCAULT, 1993; LÉVI-STRAUSS, 2002; BOURDIEU, 2000; 2005). A persona ${ }^{3}$ é comparada a legiões (em alusão a uma passagem do evangelho de $S$. Mateus), insinuando que os papéis sociais, e consequentemente, as personalidades, são articuladas - com maior ou menor reflexividade - em conformidade com as circunstâncias sociais que se apresentam no drama da vida cotidiana:

por minha parte conheço uma senhora... que muda de alma exterior, cinco, seis vezes
por ano. Durante a estação lírica é a ópera; cessando a estação a alma exterior substi-
tui-se por outra: um concerto, um baile do Cassino, a Rua do Ouvidor, Petrópolis...
- Essa senhora é parenta do diabo, e tem o mesmo nome: chama-se Legião... (p. 31).

Nosso autor parece sugerir que a persona é construída pelas relações e interações sociais, nas quais algumas vezes o indivíduo manipula suas identidades (papéis) para tentar realizar seus intentos e desejos (GOFFMAN, 1984), o que nos faz 
lembrar o sentido da palavra persona em latim: máscara (MAUSS, 1974a). A articulação do papel social e sua relação com a subjetividade estão, por sua vez, diretamente relacionadas às dimensões culturais nas quais este indivíduo está inserido; sua estrutura de personalidade, grosso modo, está adequada ao sistema cultural ou simbólico, sendo as dimensões desejantes da pessoa ligadas a tal sistema simbólico, para usar uma linguagem parsoniana. Ou, em outros termos, "as estruturas estruturantes" (sistema simbólico) estruturam as açōes e voliçōes da persona enquanto são "estruturadas" (reproduzidas) pelas próprias práticas de tais personas, sendo as formas de (dis) posição do mundo e no mundo inscritas pelas práticas no inconsciente individual.

Sendo assim, a práxis social é produzida por intermédio da inconsciente interiorização, por parte do indivíduo, da exterioridade (das estruturas culturais) e exteriorização - em sua vida cotidiana empírica (prática) e simbólica - dessa mesma interioridade absorvida pela socialização. Tal processo, denominado por Bourdieu de habitus (1972, p. 172), permite a reprodução das estruturas simbólicas e práticas constitutivas das sociedades com suas diferenças e desigualdades características. Contudo, não sendo um processo mecânico, essa dinâmica sempre está aberta a negociações do self com ele mesmo e com outros, a avaliações estratégicas do contexto e a constantes percepçóes de táticas a serem articuladas que permitam os indivíduos superar, criar ou subverter situações que os impedem de agir, os oprimem ou incomodam através de diferentes níveis de reflexividade (DOMINGUES; 1999; BOURDIEU, 2001; DE CERTEAU, 2002).

\section{A construção social da identidade}

A personagem Jacobina realiza um périplo sociológico ao demonstrar através da descrição de suas experiências a (des)construção de sua identidade (ou alma interior) dissolvida pela ausência gradativa das relações sociais perpassadas pela estrutura de poder constitutiva da cultura na qual ele mesmo estava inserido. Sua ascensão social ligada a uma promoção ao cargo de alferes da guarda nacional indica a construção social de sua pessoa, que surge como produto de relaçôes hierárquicas que lhe proporcionam regalias, status, beleza e bens materiais; identidade ligada a um papel social, enfim:

Tinha vinte e cinco anos, era pobre, e acabava de ser nomeado alferes da guarda nacional. Não imaginam o acontecimento que isto foi em nossa casa. Minha mãe ficou tão orgulhosa! Tão contente! Chamava-me o seu alferes. Na vila, note-se bem, houve 
alguns despeitados... e o motivo não foi outro senão que o posto tinha muitos candi-

datos e que estes perderam... O certo é que todas essas coisas, carinhos, atenções, obséquios fizeram em mim uma transformação que o natural sentimento da mocidade ajudou e completou. $O$ alferes eliminou o homem... aconteceu então que a alma exterior, que era dantes o sol, o ar, o campo, os olhos das moças, mudou de natureza e passou a ser a cortesia e os rapapés da casa tudo o que me falava do posto, nada que me falava do homem. A única parte que ficou comigo foi aquela que entendia com o exercício da patente; a outra dispersou-se no ar e no passado. (p. 32-5, grifo nosso).

Com o ritual que institui sua promoção - novo papel - e consequente ascensão social Jacobina sofre uma mudança radical passando de dominado socialmente a dominante. Esta mudança chega a inebriá-lo, fazendo-o perder o anterior sentido da existência e, por conseguinte, construir suas açôes em conformidade com aquilo que o senso comum exige daqueles que representam a autoridade. As estruturas sociais de dominação e sucesso fazem com que esqueça a angústia e o sentimento anterior de despossuído de bens e símbolos de status, levando-o a se tornar uma peça do sistema - um dispositivo, espécie de mecanismo. Sua alma interior mudara devido à ação de forças sociais centrípetas: "As dores humanas, as alegrias humanas... mal obtinham de mim uma compaixão apática ou um sorriso de favor. No fim de três semanas era outro, totalmente outro. Era exclusivamente alferes" (p. 35). O personagem assim representa um processo sociológico no qual a concepção individualista de mundo, concepção que poderia ser comparada ao do self made man, com toda sua carga de egocentrismo, orgulho e pedantismo, acaba por obliterar uma possível solidariedade calcada na prática da dádiva e da reciprocidade (MAUSS, 1974b; BOURDIEU, 1996).

Contudo, o individualismo manifesto como sugere Machado está associado a uma ordem social personalista e hierárquica Esse amálgama de holismo e individualismo, (DA MATTA, 2000) desemboca nos vários autoritarismos, personalismos, clientelismo e apropriação privada da coisa pública. A paixão pela máquina do Estado presente em nossa cultura surge no conto através do valor dado pela sociedade da época - e ainda hoje - ao emprego público visto desde o Ancien Régime como forma de ascensão social, estabilidade e mesmo enobrecimento (WEHLING; WEHLING, 2000). No Brasil Império, após a guerra do Paraguai, os militares foram gradativamente conquistando status e participação efetiva nos quadros político-administrativos do Estado, fato que foi aumentando até a proclamação da República (RIBEIRO JUNIOR, 1973). Na época só havia duas vias para jovens de camadas baixas e urbanas conquistarem 
um diploma de curso superior e o prestígio e ascensão social a ele relacionado: a via da Igreja, por intermédio dos seminários, e a das escolas técnicas do Exército. Nestas últimas, os estudantes se interessavam mais pelo diploma de engenharia e de outras áreas relacionadas ao avanço tecnológico disseminado pela Europa e Estados Unidos que mais propriamente pelo serviço militar (NEEDELL, 1993). Assim, é possível situar sócio-historicamente o personagem de Machado de Assis compreendendo melhor as angústias e singularidades de sua época, sem, contudo, descartar a universalidade conceitual presente no conto.

\section{Reflexividade e síntese teórica}

Jacobina viaja para o sítio de uma tia, D. Marcolina, que o adula devido ao seu cargo recém-adquirido. $\mathrm{Na}$ casa, além de ser tratado com todas as honras possíveis por parentes, o escravos, o alferes ganha a peça mais cara da residência: um grande espelho adornado com ouro, madrepérolas e delfins esculpidos que a mesma tia havia herdado de sua mãe, "esta o comprara a uma das fidalgas vindas em 1808 com a corte de D. João VI... [o espelho] era a tradição” (p. 34). Contudo, repentinamente a tia de Jacobina recebe a notícia que uma de suas filhas casada com um lavrador residente a cinco léguas de distância do sítio está à beira da morte, fazendo com que ela, a tia, e seu companheiro se retirem de cena, deixando o personagem principal sozinho com a responsabilidade de administrar as terras, os animais e os escravos. Estes últimos, aproveitando a situação, fogem logo após a partida de tia Marcolina, deixando Jacobina na mais completa solidão.

Diante do crescente vazio representado pela ausência total de relações sociais, o personagem se depara com a decomposição de sua personalidade, ou melhor, com a fragmentação de sua alma exterior, e mesmo com a possibilidade de destruição de sua sanidade, visto que sua alma interior, sua psique, estava diretamente sustentada pelo papel social que ele exercia. A violência simbólica causada pela ausência de significados positivos de sua imagem conduz o personagem a um estado de letargia e quase-morte - ou melhor, sua morte social, se prolongada, ameaça sua vida enquanto ser biológico. É neste momento de total solidão e angústia que Jacobina percebe repentinamente sua insignificância diante do mundo; na possibilidade da morte social, Jacobina se defronta com a morte de fato, com o vazio, o nada, a falta total de sentido da existência. 
Vale ressaltar que Machado de Assis neste momento evoca um "diálogo do abismo" um "cochicho do nada" (p. 31), reiterando a perda, por parte do personagem, da própria condição humana. Condição possível apenas na forma relacional. $\mathrm{O}$ autor parece nos dizer: ser humano apenas é possível em sociedade - relacionalmente, são as ficções coletivas (valores, costumes, regras, formas de perceber o mundo, e, portanto, hierarquizá-lo e nele agir etc.) que conjugam os sentidos e significados das existências individuais.

Conforme sugere Bourdieu, a sociedade é uma ficção coletiva que deixa de ser ficção por ser coletiva. Fora do quadro simbólico tecido pelo coletivo, não há possibilidade de vida humana em seu sentido integral. Jacobina torna-se "como um defunto" (p. 38), e diz que viver na solidão é ainda pior que ter morrido (p. 37). Neste instante, existência e relação social são sinônimos.

A certa altura, o que restará de sociedade na vida de Jacobina resumir-se-á aos sonhos; toda a dimensão de sentido de sua vida terá como alicerce as dimensōes simbólicas inscritas no seu inconsciente sedento de relações sociais:

Nos sonhos fardava-me, orgulhosamente, no meio da família e dos amigos, que me elogiavam o garbo, que me chamavam alferes; vinha um amigo de nossa casa, e prometiame o posto de tenente, outro o de capitão ou major; e tudo isso fazia-me viver (p. 39).

Será através do sentido de dois objetos: o espelho, ${ }^{4}$ signo da tradição, e a farda, signo da relação social, vínculo da sua persona com o socius através da função exercida pelo papel social, que Jacobina começará - após ter encarado o abismo da solidão e o vazio da angústia de ser ninguém ou nada - a reestruturar, significar sua existência. ${ }^{5}$ A farda surge no conto como espécie de objeto relacional que permite à personagem manter sua integridade psicológica até o momento de reintegrar-se à sociedade com o retorno dos seres humanos ao sítio. A personagem, ao encarar-se no espelho (o qual até então não havia sido utilizado), em um primeiro momento, não se reconhece, pois havia perdido sua alma exterior e, portanto, sua identidade. Apenas quando se lembra de vestir a farda (símbolo da autoridade das estruturas sociais, par excellence) diante do mesmo é que sua identidade retorna:

$\mathrm{O}$ vidro reproduziu a figura integral; nenhuma linha de menos; nenhum contorno diverso; era eu mesmo, o alferes, que achava, enfim, a alma exterior. Essa alma ausente com a dona do sítio, dispersa e fugida com os escravos, ei-la recolhida no espelho (p. 42).

A lógica presente nas relações entre os signos que Jacobina articula remete a uma estrutura na qual o espelho está para a alma interior, assim como a farda 
está para a alma exterior. Espelho e farda são dois termos que se completam, assim como indivíduo e sociedade; mas nessa adequação, relações de poder se manifestam através de signos: a farda, símbolo das estruturas empíricas (objetivas) remete diretamente às hierarquias sociais, as desigualdades que produzem e são produzidas pelas relações entre os homens em sociedades complexas.

Tal hierarquia se inscreve na mais profunda dimensão do sistema simbólico, o inconsciente. Jacobina sonha e nos seus sonhos seu papel de alferes, de autoridade está presente conferindo sentido ao seu ser. Já o espelho constitui-se, não apenas como instrumento que reflete a imagem, mas como o próprio self, a própria alma interior que tem inscrito no seu fundo mais recôndito a exterioridade, o dentro. Neste sentido, o interior apresentar-se-ia como uma dobra do exterior, do fora (DELEUZE, 2007), sendo as situaçōes limites - a angústia, o estar face a face com o vazio, a ausência de sentido, a estruturalidade da estrutura - um caminho possível para a reflexividade, ou seja, para a percepção da condição trágica viabilizada por um olhar crítico capaz de compreender o funcionamento das estruturas de reprodução social e desencantamento do mundo.

É na angústia de sua situação de morte social que Jacobina pode manifestar sua reflexividade - pensamento crítico - que o permite compreender a construção social da pessoa e os aspectos inerentes a uma sociedade individualista que tenta esconder - sem nunca plenamente conseguir - a existência de um multividuo (VIVEIROS DE CASTRO, 2002) em contraposição a sua ideologia individualista. $\mathrm{O}$ indivíduo é um múltiplo, um eu fragmentado, que comporta na sua unidade aparente toda a história de sua cultura e estruturas sociais. Nas palavras de Marx:

Os homens fazem sua própria história, mas não a fazem como querem; não a fazem sob circunstâncias de sua escolha e sim com aquelas que se defrontam diretamente, legadas e transmitidas pelo passado. A tradição de todas as gerações mortas oprime como um pesadelo o cérebro dos vivos (MARX, 1978, p. 329).

Apenas através de uma fuga para interioridade (dor existencial), reflexo da exterioridade é que o "sujeito" se depararia com a possibilidade de encontrar uma via para a percepção do todo social com sua carga de ficção e ilusão pesando sobre a construção do "indivíduo" como conceito.

É na angústia ao deparar-se com o abismo que Jacobina sente-se coisa, vazio, nada e passa a traçar a possível consciência de sua existência como ser (HEIDEGGER, 2006). Este movimento talvez abra uma das possibilidades para 
um tipo de reflexividade que viabilize o surgimento de solidariedades focais, novos saberes e novas práticas sociais (LUZ, 2003) que venham articular novas estratégias de sobrevivência em uma era de massificação e transformação do ser humano em mercadoria e objeto de consumo. Pode ser que este processo seja possível pela experiência do que Weber denominou desencantamento do mundo e falta de sentido da vida sofrida por indivíduos e grupos, levando-os a realizarem novas possibilidades de existência. Essa realização tanto poderia ser individual (pertencer ao registro da individuação, para usar um termo menos metafísico, já que é o multivíduo o cerne do processo), como coletiva; com alta ou baixa carga de reflexividade, diversos níveis de subjetividade (ou subjetivação) e intencionalidade (DOMINGUES, 1999; 2004).

Não temos o objetivo e a pretensão de escrever uma teoria da mudança social baseada na insatisfação do ator, mas apenas apontar um dos possíveis fatores (já detectados indiretamente na arte de Machado de Assis) das dinâmicas sociais. Emoções, tanto coletivas como individuais, devem ser levadas em conta quando tratamos destas dinâmicas (DOMINGUES, 1999; BOURDIEU, 2001), visto que podem descentrar ou desestabilizar estruturas e práticas caracterizadas por baixa reflexividade, levando aquele(s) que atravessa $(\mathrm{m})$ concretamente o abalo a buscar $(\mathrm{em})$ reorganizar suas dimensões cognitivas, morais, éticas e, portanto, práticas.

Jacobina-Machado, "astuto e cáustico" (p. 29) foi um exemplo (embora na ficção) de realização de nova subjetivação efetuada pelo experimento de uma situação limite de (des)construção de sua pessoa e mundo. Tal experiência produziu-lhe o entendimento reflexivo de sua individuação, permitindo-lhe suplantar a ideia metafísica de sujeito. Ao se recolher no seu mais profundo eu, o personagem encontra o reflexo do todo social e a percepção que a existência é muito mais - e até mesmo o avesso - da rotina desencantada de um sistema social individualista. Sistema calcado na desigualdade que oblitera a criatividade de novas formas de vida (ENNE, 2005; PELOGGIO, 2005) subsumindo a diferença à metafísica da identidade. Neste aspecto, vale destacar que Sujeito é concepção típica da metafísica ocidental a qual separa o ser do ente - em outras palavras, um suposto mundo verdadeiro transcendente do mundo dito imanente (das aparências e simulacros), buscando no primeiro a causa do segundo.

Arriscamos afirmar que esse processo se constituiu como história de uma distorção ao ignorar os aspectos corpóreos e biológicos que sustentam as intenções 
de todo discurso, principalmente o metafísico (CSORDAS, 1994; 1999; BOURDIEU, 2001; MEARLEU-PONTY, 2006). Tais aspectos levam o ser humano a esquecer o caráter "ilusório" de seu conhecimento (e de toda cultura), fazendo-o confundir a lógica de seu pensamento com a lógica do mundo e a supor a existência de uma identidade atemporal e imutável. A ideia de Sujeito (hypokeimenon: algo que se encontra sob o ente) que surge na Grécia clássica paralela ao surgimento da metafísica e se torna parte da Weltanschauung medieval e moderna - o Subjectum (em latim) -, elevando uma distorção a categoria de conceito. A concepção de Sujeito e Indivíduo reverbera a visão metafísica de que tudo que é real apresenta um sustentáculo ideal (espiritual) que é imutável e imperecível em contraposição ao Devir.

$\mathrm{Na}$ filosofia cartesiana e kantiana, a ideia de Subjectum consegue adquirir um arcabouço teórico racionalista construtor de um sujeito autônomo como medida da Verdade; em Descartes este sujeito põe o ente a medida que o representa; e em Kant, surgem os limites deste sujeito que se lança na empreitada de conhecer os entes (NIETZSCHE, 2000; 2002; KAHLMEYER-MERTENS, 2003; DE LA ROCA TAVARES, 2003). Tais concepções individualistas surgirão na sociologia com os teóricos radicais da ação que confundem o indivíduo cartesiano e iluminista com o processo de individuação presente na tradição do pensamento pós-romântico alemão, representado principalmente por Weber (1995). Tais autores apresentam a tendência a interpretar a vida social como produto da ação individual guiada por uma reflexividade centrada e onipresente, muitas vezes misturando uma interpretação weberiana por demais acionalista com um tipo de fenomenologia demasiado cartesiano, além do liberalismo econômico (p. ex., BOUDON 1995; ELSTER, 1994).

Ao refletir a sociedade e seus aspectos pertinentes, por intermédio da imagem do indivíduo, o espelho reflete também a angústia de uma época e de alguém (ou alguns, no caso de grupos) que, através dela, pode chegar à reflexividade e à subjetivação, atuando no mundo sem se tornar unicamente reflexo deste.

\section{Referências}

BOUDON, R. Tratado de sociologia. Rio de Janeiro: Jorge Zahar, 1995. 604p.

BOURDIEU, P. Esquisse d'une théorie de la pratique. Genève: Droz. 1972. 224p.

. O poder simbólico. Lisboa: Difel, 1989. 328p. 
Marginália. Algumas notas adicionais sobre o dom. Mana. Estudo de Antropologia

Social. PPGSA/UFRJ, Rio de Janeiro, v. II, n. II, p. 7-20, out. 1996.

. A dominação masculina. Rio de Janeiro: Bertrand Brasil, 2000. 160p.

. Meditaçôes pascalianas. Rio de Janeiro: Bertrand Brasil, 2001. 320p.

. As Regras da Arte. São Paulo: Companhia das Letras, 2002. 432.p.

. Esboço de auto-análise. São Paulo: Companhia das Letras, 2005. 144.p.

CSORDAS, T. Embodiment and experience. In: . The existencial ground of culture and self. Cambridge: Polity Press, 1994. 306p.

. The body's carrier in anthropology. In: Anthropological theory today. Cam-

bridge: Polity Press. 1999. p. 172-205.

DA MATTA, R. Estado e sociedade e a casa e a rua. In: DEL PRIORE, M. Revisão do Paraíso. Os brasileiros e o Estado em 500 anos de História. São Paulo: Companhia das Letras, 2000.

DE CERTEAU, M. A Invenção do cotidiano. 1. Artes de Fazer. Petrópolis: Vozes, 2002. 351p.

DE LA ROCA TAVARES, M.E. A crítica nietszcheana do conceito de identidade. In: FEITOSA, C.; BARRRENACHEA, M.; PINHEIRO, P. (Org.). A Fidelidade à Terra. Rio de Janeiro: DP\&A, 2003. pp. 381-388.

DELEUZE, G.; GUATTARI, F. O que é a Filosofia? Rio de Janeiro: Ed. 34, 1993.288.p. . A dobra. Leibniz e o Barroco. São Paulo: Papirus, 2007. 232p.

Lógica do Sentido São Paulo: Perspectiva, 2000. 342p.

DERRIDA, J. Estrutura, signo e jogo no discurso das ciências humanas. In: MACKESEY; DONATO (Org.). A controvérsia estruturalista. São Paulo: Cultrix, 1976. p. 260-274. . Gramatologia. São Paulo: Perspectiva, 2004. 341p.

DOMINGUES, J.M. Ensaios de sociologia. Teoria e pesquisa. Belo Horizonte: Ed. UFMG. 2004. 262p.

. Teorias sociológicas do século XX. Rio de Janeiro: Civilização Brasileira, 2001. 110 p. . Criatividade social, subjetividade coletiva e a modernidade brasileira contemporânea. Rio de Janeiro: Contra Capa Livraria, 1999. 270 p.

DUMONT, L. Homo Hierarchicus. O sistema de castas e suas implicações. São Paulo: Edusp, 1997.424p.

DURKHEIM, E.; MAUSS, M. Algumas formas primitivas de classificação. In: RODRIGUES, J.A. (Org.). Durkheim. Rio de Janeiro: Ática, 2001. p.183-203 (Col. Grandes Cientistas Sociais, v. I.).

ELSTER, J. Peças e engrenagens das ciências sociais. Rio de Janeiro: Relume-Dumará, 1994. 212p. 
ENNE, A. O defensor do indivíduo: Hermann Hesse e o processo de massificação nas primeiras décadas do século XX. In: ALCEU. Revista de Comunicação, Cultura e Política, Rio de Janeiro, v. 5, n. 10, jan-jun 2005.

FOUCAULT, M. Microfisica do poder. Rio de Janeiro: Graal, 1993.294p.

GOFFMAN, E. The presentation of self in everyday life. Chicago: Anchor Books, 1962.

HEGEL, G.W. Fenomenologia do espirito. Obras incompletas (Os Pensadores). São Paulo: Abril Cultural, 1978.

HEIDEGGER, M. Ser e tempo. Petrópolis: Vozes, 2006. 598p.

RIBEIRO JÚNIOR, J O Brasil monárquico em face das repúblicas americanas. In: MOTTA, C.G. (Org.). Brasil em perspectiva. São Paulo: Rio de Janeiro, 1973.

KAHLMEYER-MERTENS, R.S. Nietzsche. Metafísica, errância e subjetividade. In: FEITOSA, C.; BORRENACHEA, M.; PINHEIRO, P. (Org.). A Fidelidade à Terra. Rio de Janeiro: DP\&A, 2003. p. 399-406.

LACAN, J. Escritos. Rio de Janeiro: Jorge Zahar, 1998. 944 p.

LEVI-STRAUSS, C. Introdução à obra de Marcel Mauss. In: MAUSS, M. Sociologia e antropologia. São Paulo: EPU/EDUSP, 1974. p. 1-48.

. O pensamento selvagem. São Paulo: Papirus, 2002. 324p.

LIEDKE, E.R. Breves indicações para o ensino de teoria sociológica hoje. Sociologias. Porto Alegre, ano 9, n. 17, p. 266-278, jan/jun.

LUZ, M.T. Novos saberes e práticas em Saúde Coletiva. São Paulo: Hucitec, 2003. 174p.

MACHADO DE ASSIS, J. M. O Espelho. Esboço de uma teoria da alma humana. In: . Contos. Porto Alegre: LP\& M, 1998. 120 p.

MARX, K. O 18 Brumário de Luis Bonaparte. São Paulo: Abril Cultural, 1978. 144p. (Col. Os Pensadores).

MAUSS, M. Uma categoria do espírito humano: a noção de pessoa. A noção do "eu". In: . (Org.) Sociologia e antropologia. V. I. São Paulo: EPU/Edusp, 1974a p. 207-241. Ensaio sobre a dádiva. Forma e razão da troca nas sociedades arcaicas. In:

(Org.). Sociologia e antropologia. V. II. São Paulo: EPU/Edusp, 1974b. p. 37-148.

MEAD, G.H. Mind, self and society. Chicago: Chicago University Press, 1963. 278p.

MERLEAU-PONTY, M. Fenomenologia da percepção. São Paulo: Martins Fontes, 2006. 662 p.

NEEDELL, J. Belle Époque tropical. São Paulo: Companhia das Letras, 1993.

NIETZSCHE, F. O crepúsculo dos ídolos. São Paulo:Companhia das Letras, 2006. 160p. . A Gaia ciência. São Paulo: Companhia das Letras, 2002. 376p.

PARSONS, T. El sistema social. México: Alianza, 1999. 534p. 
PELOGGIO, M. Da historicidade: perdas e ganhos na crítica benjaminiana. Alceu. Revista de Comunicação, Cultura e Política. Rio de Janeiro, v. 5, n. 10, jan-jun. 2005.

SCHNAIDERMAN, B. Dostoiéveski: A ficção como pensamento. In: NOVAES, A. Artepensamento. São Paulo: Companhia das Letras, 1994.

VERNANT, J.P. A tragédia grega: problemas de interpretação. In: MACKESEY, R.; DONATO, E. (Org.). A controvérsia estruturalista. São Paulo: Cultrix, 1976. p. 285-324.

VIVEIROS DE CASTRO, E. A inconstância da alma selvagem. São Paulo: Cossac \& Naif, 2002. 552p.

WEBER, M. Economia y sociedad. México: Fondo de Cultura Económica, 1995. 1195p.

WEHLING, A.; WEHLING, M.J. O funcionário colonial entre a sociedade e o rei. In: DEL PRIORE, M. Revisão do paraíso. Os brasileiros e o Estado em 500 anos de História. São Paulo: Companhia das Letras, 2000.

\section{Notas}

${ }^{1}$ Pensamento aqui é entendido como processo de busca constante de apreensão do universo; recortes cognitivos que conferem um sentido ao caos como sugerem Deleuze e Guattari (1993, p. 254): Pensar é pensar por conceitos [filosofia], ou então por funções [ciência], ou ainda por sensações, [arte] e um desses pensamentos não é melhor que outro, ou mais plenamente, ou mais completamente, mais sinteticamente 'pensado'”. Estas três dimensões, por vezes, produzem interseçôes, pontos de cruzamento, espaços compartilhados, ecos.

${ }^{2}$ Machado de Assis remete a esta estrutura inescapável quando sugere a existência de hierarquia até nos céus ao referir-se a serafins e querubins (p. 29). Desta forma, alude ao fato de que todo sistema simbólico tem por alicerce a diferença; esta certamente não implica desigualdade, mas o sentido metafísico da cultura ocidental apresenta a tendência de subsumi-la a identidade desdobrando tal processo, disfarçado de movimento pela lógica dialética, em reprodução do desigual e não da diferença (DERRIDA, 2004; DELEUZE, 2000; DUMONT, 1997).

${ }^{3} \mathrm{O}$ termo remete diretamente aos estudos de Mauss sobre a invenção da categoria "eu". De acordo com o autor, a concepção de persona na maioria das culturas antigas e também não ocidentais estaria relacionada ao papel investido circunstancialmente e socialmente pelo agente. Ele usaria uma máscara - este é o sentido da categoria- ou articularia e associaria devires que manifestaria por sua vez a classificação social e sua consequente hierarquia anterior ao agente.

${ }^{4}$ Lacan (1998), em seus escritos sobre a fase do espelho, destaca o momento em que a criança se percebe no Outro, construindo sua identidade interior (função do eu) pelo exterior (fora) em uma relação complementar. De forma similar, Mead (1963) criou o conceito de eu - espelho para tentar dar conta do aspecto interativo e, portanto, social, da construção do self.

${ }^{5}$ Sentimento de solidão que toma conta de Jacobina após a fuga dos últimos seres humanos com os quais mantinha contato reitera o caráter sistêmico (relacional) das articulaçôes de poder nas quais, enquanto o sentido de sua existência apenas em relação a outro termo (dominados), que se apresenta como fiador do sentido da dominação. 


\title{
Abstract
}

\author{
Mirror of the soul. Subjectivity and Social \\ Theory in a short history by Machado de Assis \\ This paper aims to present a brief outline of the \\ theoretical intersections in the short history "The looking \\ glass. Rough draft of a new theory of the human soul”, by \\ Machado de Assis. It departs from the tradiction of social \\ theory that suggests a sociological syntheses between \\ action and strutcture that is closely linked to the issue of \\ one's construction of identity and subjectivaction, their \\ reproduction and social transformation.
}

> Key words: social theory; subjectivation; sociological synthesis; identity. 